\title{
Assessment of Electric Vehicles Promotion Measures at the National and Local Administrative Levels
}

\author{
Povilas Maciulis ${ }^{1}$, Inga Konstantinaviciute ${ }^{2}$, Vaida Pilinkiene ${ }^{3}$ \\ ${ }^{1,2}$ Lithuanian Energy Institute \\ Breslaujos st. 3, 44403 Kaunas, Lithuania \\ E-mail.povilas.maciulis@lei.lt, inga.konstantinaviciute@lei.lt \\ ${ }^{3}$ Kaunas University of Technology, \\ K. Donelaicio st. 73, 44249 Kaunas, Lithuania \\ E-mail.vaida.pilinkiene@ktu.lt
}

cross $^{\text {ref }} \underline{\text { http://dx.doi.org/10.5755/j01.ee.29.4.19960 }}$

The transport sector is one of the major emitters of greenhouse gases and other pollutants. Transition from usage of fossil fuels to usage of renewable energy resources calls for a comprehensive package of national and local actions. Although electric vehicles can significantly contribute to energy consumption efficiency, reduction of carbon dioxide emissions and independence from petroleum imports, electric vehicle market development in some countries remains comparatively slow. Electric vehicles are more expensive in comparison to traditional vehicles, countries lack necessary infrastructures, consumers may need additional information about the benefits of eco-friendly cars, etc. The above-mentioned and other weighty reasons force national and local authorities to think about the implementation of financial and non-financial electric vehicle promotion measures. The experience of other countries and cities is extremely valuable as it helps to form the trends and exploit the benefits of the best practice. Previous studies consider the impact of the measures of electric vehicle usage promotion in insufficient detail. Comprehensive analysis is needed to determine the effectiveness of promotional measures, their planning and forecasting. The potential resources for and the experience of implementation of such measures are poorly researched, which determined the goal of this article: to assess the most common electric vehicle promotion measures at different administrative or authority levels.

Keywords: Electric Vehicle; Promoting System; Administrative Level; National and Local Authorities.

\section{Introduction}

Although electric vehicles can significantly contribute to energy consumption efficiency, reduction of carbon dioxide emissions and independence from petroleum imports, numerous technical and economic challenges burden electric vehicle mass-market adoption (Kley et al., 2010). Having faced the problems of air quality decrease, a number of countries worldwide are striving to promote electric vehicle usage. One of the reasons why natural market entry for electric vehicles is relatively slow can be linked to their prices, which are higher than the prices of traditional fossil fuel-driven vehicles. Trying to improve the situation, national and local authorities develop promotive policy instruments which enhance competitiveness of electric vehicles and increase their popularity among consumers (Yang et al., 2016). Significant public interest in electromotive technologies and the environmental impact of these technologies determines topicality of such problems as efficiency and effects of electric vehicle promotion measures researched by Hall et al. (2017), Hall and Lutsey (2017), Jin and Slowik (2017), Yang et al. (2016), Mock and Yang (2014), Alhulail and Takeuchi (2014), Windisch (2013), Perdiguero and Jimenez (2012), and many other authors. In terms of promotion of the transition from traditional fossil fuel-driven vehicles to electric vehicles, local authorities do not lag behind national authorities and demonstrate the ability to significantly reduce carbon emissions in the transport sector. Even after incorporating upstream emissions, electric vehicles provide a carbon emission reduction advantage, which in Chinese, European and the U.S. markets varies from $30 \%$ to over $98 \%$ in comparison to the statistics of traditional fossil fuel-driven vehicles. In the area of electric vehicle promotion, contribution of not only car manufacturers but also energy producers is essential, especially in terms of energy decarbonisation (Hall et al., 2017).

Nevertheless, electric vehicle promotion systems, measures and even goals may significantly vary at different levels: some of them are implemented at a national level, while others are orientated towards local resources and focus areas (Yang et al., 2016). Particular effects can also be caused by some other determinants. For instance, Alhulail and Takeuchi (2014) note that the sales of ecofriendly cars can be significantly affected by fuel prices, car model prices and population income. Fuel prices, however, are not stable, and even if high prices can affect the sales of eco-friendly cars, these changes can turn out to be only temporary.

The subject of this article is the assessment of the promotion measures at various administrative levels, and the object of the research is measures to promote electric 
vehicles. Previous studies consider the impact of the measures of electric vehicle usage promotion on national and/or regional economics in insufficient detail. Comprehensive analysis is needed to determine the effectiveness of promotional measures, their planning and forecasting. The potential resources for and the experience of implementation of such measures are poorly researched, which determined the goal of this article: to assess the most common electric vehicle promotion measures at different administrative or authority levels.

This article consists of three parts. The beginning is focused on the identification of measures which are implemented at national level. The second part emphasizes the most commonly used measures at the municipality level. In the last part authors present the assessment of policy frameworks implemented by different authorities, which is summarized in the conclusions. When comparing the role of different authorities in the implementation of electric vehicle promotion measures and assessing different policy frameworks, the methods of systematic, comparative and logical analysis were applied in the paper.

\section{The Role of Administrative Levels in the Electric Vehicle Promotion Measures}

Scientific publications propose different classifications of electric vehicle promotion measures. For instance, electric vehicle promotion measures can be classified by their character, volume or administrative level. IEA-RETD (2015) proposes segmentation by administrative levels and separation by three dimensions: vehicles, energy infrastructure and energy carries. This model not only distinguishes particular administrative levels (measure suppliers), but also reveals orientation of the measures by three dimensions. As it was noted by Kley et al. (2010), the measures themselves follow different steps in the value chain. In spite of the fact that the largest part of the measures focus on manufacturers and infrastructure, the main target of price promotions is a direct final consumer, i.e. an individual or a fleet.

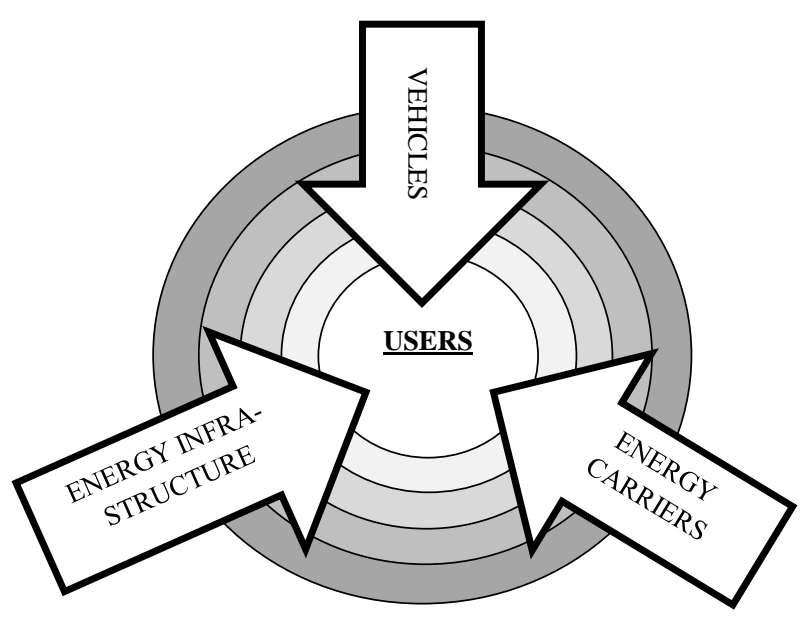

\begin{tabular}{|l|l|}
\cline { 2 - 2 } \multicolumn{1}{c|}{} & Administrative levels \\
\hline & Federal / Union \\
\hline & National / State \\
\hline & Local \\
\hline & Industry \\
\hline
\end{tabular}

Figure 1. Three Dimensions of Policies in Relation to Different Administrative Levels (IEA-RETD, 2015)

The scheme of the administrative levels, proposed by IEA-RETD (2015), is also followed by Leviakangas et al. (2014), Windisch (2013), Cluzel et al. (2013), Perdiguero and Jimenez (2012), Hanley (2011), Gallagher and Muehlegger (2011) and other authors. The authors of this article consider that classification of the measures by the above-introduced scheme of administrative levels is relevant as it shows the limits of responsibilities and reveals the issues of resource distribution. Comparison of local and national measures is incongruous due to the differences in local and national resource bases and legal frameworks, which, in turn, calls for separate assessment of local and national electric vehicle promotion systems. It can be argued that administrative systems also cover some middle levels (e.g. regions), which may possess their own electric vehicle promotion measures, but to simplify the research, the authors of this article focus only on two basic administrative levels - local and national.

Summarising, it can be stated that consideration of a character and purpose of a promotion measure allows to identify the appropriate administrative level in which the decision on implementation and monitoring of the measure will be made. Nevertheless, different countries may follow different practices. For instance, for achievement of the defined aims, China introduces the essential fiscal subsidies at the national and sub-national levels (ICCT, 2017). Norway implements the main promotion measures at the national and regional levels (Hall et al., 2017). Mersky et al. (2016) notes that although many European countries implement promotion measures at different administrative levels ranging from nation to regional or local, Norway is unique in this regard as it implements the countrywide policy which covers all the main categories of promotion benefits: infrastructure usage pricing benefits, infrastructure access benefits, point of sale pricing benefits, parking access and charging access benefits. The only category of promotion benefits not covered at the national level in Norway is fuel price benefits. Fuel price benefits are covered at the regional level. 


\section{The Role of National Authorities}

There is no doubt that national authorities play a very important role in promotion of electric vehicles. The structures of national and international policies, aimed at promotion of eco-friendly cars, perfectly suit for making good progress. According to Hanley (2011), most of the cases reflect the reality that national kick-start funding systems are extremely effective in initial stages of electric vehicle development. Standardisation, which ensures electric vehicle interaction inside and outside the country, definitions of deployment targets, financial initiatives, regulations (including building codes) and permits serve as the main promotion instruments (IEA/OECD, 2017). The alternative to the financial mechanisms that ensure direct or indirect grants for electric vehicle buyers and users is diesel and petrol vehicle taxation aimed at making the latter types of vehicles less popular. For instance, Norway taxes cars with internal combustion engines at extremely high rates (Mock \& Yang, 2014). Following the polluter-pays principle, national authorities tax heavily polluting vehicles at very high rates, while eco-friendly vehicles are exempted from taxes. Combination of fiscal and other target measures helps Norwegian cities to occupy leading positions at the forefront of electric vehicle deployment and integration, including introduction of low annual road taxes, no fuel taxes, no purchase or import taxes, free parking, bus lane access, free charging, extensive public charging network, and exemption from road and tunnel tolls (Hall et al., 2017). In addition, Norway possesses the experience in provision of the consistent long-term support, which has conditioned maturity of the domestic car market and enhanced visibility of electric vehicles, which serves as an important determinant of the spread of new technologies (Eppstein et al., 2011).

As electric vehicles can be referred to as fast developing technologies, national authorities can actively collaborate with car manufacturers in the areas of new product creation and investment in research and development. Some countries, such as Germany or China, have established special territories where integration projects, new charging infrastructure technologies and consumer outreach programmes are tried out. This contributes to the development of the best practice which is later implemented in other territories (Hall et al., 2017). Mersky et al. (2016) presents the example of Norway where the measures of commercialisation were introduced in the initial stage of electric vehicle usage promotion. From 1990 to 1999, such measures as vehicle-related tax exemptions, toll exemptions and free parking in spaces owned by certain municipalities were employed. Although the largest part of the measures are consumer-oriented, Mock and Yang (2014) note that orientation towards car manufacturers (for example, research and development funding) is no less important. In this respect, a significant role can be played by universities, especially in terms of electric vehicle technology development and consumer/driver behaviour and expectation research. In the fast-growing field of vehiclegrid integration, electric power utilities have started worldwide scientific research and testing related to new charging infrastructures and their impacts, in particular, in the area of smart charging. Hall et al. (2017) agree that scientific studies and consumer campaigns should be treated as growth determinants because they help to involve the stakeholders and raise the awareness and knowledge of the changes in electric vehicles and availability of the models. Both public institutions and the private sector can define their different aims of electric vehicle promotion (IEA/OECD, 2017). Hall et al. (2017) presents the example of China where in 2015 the national government set the aims to have at least one charging station and 2000 electric vehicles, while by 2020 they pursue to create the infrastructure which would be able to serve 5 million electric vehicles. National authorities can also clearly show the markets that even larger numbers of electric vehicles will be required in the future. Local authorities undoubtedly play an important role in defining the demand for municipal cars, public transport or service vehicles, for instance, garbage trucks (IEA/OECD, 2017). Green public procurement policies and practices are applied for the technologies which have previously been tested and found suitable for the market, but which are currently lacking a commercial potential to be transferred to the main markets. Xylia and Silveira (2017) demonstrate how substantially green public procurement has contributed to the usage of renewable fuels in the sector of public transport over the last few years: in 2014 , nearly $58 \%$ of the total number of public transport kilometres in Sweden were covered with the vehicles driven on non-fossil fuels (in $2007-8 \%$ ).

Further in the article, we will discuss three main blocks of electric vehicle promotion measures related to the responsibilities of national authorities. The blocks include charging infrastructure, financial initiatives \& regulations.

Charging infrastructure. As it was noted by Gao et al. (2015), national authorities actively co-operate with vehicle and utility services companies as well as with other infrastructure providers for the development of the national standards for charging stations and their networks. The standards and technical norms have to be developed so as to secure electric vehicle access to power grids for recharging. In order to prevent so-called technological islands and achieve the economies of scale, the global standards have to be developed (Leviakangas et al., 2014). International cooperation is also possible. Gao et al. (2015) introduce the standardisation initiative 'Electric Vehicle Charging Project' launched by China and Germany in 2014. Following the principles of this initiative, China and Germany work on joint technological projects, implementation procedures and vital business models for the development of charging infrastructures in both private and public areas. The principal element of this initiative is unification of charging standards so that the electric vehicles imported from any country could use local charging infrastructures. The initiatives of this type strongly encourage the investment in charging infrastructures. Accessibility and interoperability of the infrastructure as well as employment of universally acceptable methods of payment are the key implementation determinants from the position of drivers who use electric vehicles in different jurisdictions (IEA/OEC, 2017). Aiming at acceleration of the charging infrastructure development, national authorities may decide to provide the support to developers, owners, managers and consumers (Mock \& Yang, 2014). For instance, in the UK, individuals receive the support of 
about $\$ 650$ for installation of a home electric vehicle charger, while business companies are provided the grants of $\$ 400$ for arrangement of a single charging point which is due to be used for charging of both company vehicles and staff own vehicles. Such coordination is extremely important while ensuring the countrywide accessibility of power grids to different models of electric vehicles. For instance, the sales of electric vehicles in Norway soared in 2010 when the national government initiated the electric vehicle charging program (Mersky et al., 2016). Successful development of the electric vehicle charging infrastructure must also be based on careful planning. For example, Chinese government made the decision to arrange 4.3 million private outlets, 0.5 million public chargers for cars and 850 intercity quick-charge stations, among other targets for buses and taxis by 2020; in 2016, Koreans reviewed their former aim to arrange 1400 - 3000 universally acceptable quick-charge stations and make the largest part of the country electric vehicle-friendly (IEA/OEC, 2017).

Financial initiatives. Financial initiatives serve as a core driving force behind the sales of eco-friendly cars. Namely for this reason, financial initiatives are employed as a promotive measure in all large electric vehicle markets (Yang et al., 2016). According to Mock and Yang (2014), the analysis of the links between the level of promotive measures and the dynamics of electric vehicle markets proposes that these two factors are interrelated. Norway and the Netherlands are the obvious examples of how high fiscal initiatives contribute to generation of the sufficient gross value for consumers, which, in turn, determines higher electric vehicle market growth rates. Nevertheless, the results of some studies show that fiscal initiative is not the only determinant of the growth in the number of electric vehicle users. For example, despite a relatively high level of fiscal incentives, the current electric vehicle market penetration in the UK was found to be low in comparison to the market penetration in the leading countries (Mock \& Yang, 2014). There are some ways how national authorities can financially promote usage of electric vehicles. For instance, the United States grant a \$7,500 tax credit for acquisition of an electric vehicle. The credit is available for consumers at the end of the tax year. Not all consumers, however, are inclined to wait. Gallagher and Muehlegger (2011) found that consumer response to an automatic acquisition tax exemption is better than the response to the income tax credit as in the latter case a consumer has to understand the system, additionally apply to public authorities and relate the actions to tax refund. Although an acquisition tax rate is commonly lower, the research revealed that the $\$ 1,077$ value of the acquisition tax exemption is treated as the $\$ 2,011$ value of the income tax credit. It is also the case that in order to reduce electric vehicle acquisition costs, such countries as Sweden or Japan offer advance discounts. This, perhaps, is the clearest and most acceptable promotive measure from the position of consumers, although it is not necessarily cheapest from the position of national authorities (Hall et al., 2017). In some markets, electric vehicle owners have to pay lower rates of annual vehicle ownership taxes than traditional vehicle owners. For instance, in Germany the annual circulation tax is calculated by considering a vehicle's carbon dioxide emissions and engine power. Electric vehicles are exempted from this tax for the period of the next ten years from the date of the first registration (Mock and Yang, 2014). China offers an attractive one-time financial incentive which directly motivates consumers to buy electric vehicles. The combined value of the national and local subsidies amounts to $\$ 17,000$, and exemption from the sales tax serves as an additional incentive (Gao et al., 2015). The Dutch government offers substantial national subsidies which are combined with the additional incentives in particular regions (Hall et al., 2017). To support local manufacturers, Chinese government grants electric vehicle purchase subsidies for locally manufactured vehicles (Gao et al., 2015). Employment of a value added tax incentive (estimated considering the base price of a vehicle) is also common, although it should not be overlooked that value added tax rates may vary on a wide scale from $5 \%$ in Japan to $25 \%$ in Denmark, Norway and Sweden. In some markets, an extra registration fee is charged. For instance, in the Netherlands, registration fee rate depends on a vehicle's exhaust emissions (Mock \& Yang, 2014). Summary of the general financial and economic electric vehicle incentive types by Yang et al. (2016) has been presented in Table 1.

General Electric Vehicle Incentive Types and Their Timing (Yang et al., 2016, 5)

Table 1

\begin{tabular}{|c|c|c|c|c|}
\hline Category & Type & Consumer value & Typical timing & Examples \\
\hline \multirow[t]{2}{*}{ Subsidy } & Income tax credit & $\begin{array}{l}\text { A reduction of annual consumer taxes, for } \\
\text { example from } \$ 2,500-\$ 7,500 \text { per vehicle, that } \\
\text { would otherwise be paid (when there is tax } \\
\text { liability) }\end{array}$ & The end of the tax year & U.S. \\
\hline & Vehicle purchase rebate & $\begin{array}{l}\text { A check, typically } \$ 1,000-\$ 5,000 \text { per vehicle, } \\
\text { provided by the government to a vehicle } \\
\text { consumer within a set amount of time }\end{array}$ & $\begin{array}{l}\text { Within several months } \\
\text { of vehicle transaction }\end{array}$ & California, France \\
\hline \multirow[t]{2}{*}{ Tax reduction } & $\begin{array}{l}\text { One-time vehicle tax } \\
\text { reduction }\end{array}$ & $\begin{array}{l}\text { A reduction in vehicle-related taxes, ranging } \\
\text { from } 5 \% \text { up to } 80 \% \text { of the original vehicle } \\
\text { retail price }\end{array}$ & $\begin{array}{l}\text { Around the time of a } \\
\text { vehicle purchase }\end{array}$ & $\begin{array}{c}\text { Norway, } \\
\text { Washington }\end{array}$ \\
\hline & $\begin{array}{l}\text { Annual vehicle tax } \\
\text { reduction }\end{array}$ & $\begin{array}{l}\text { A reduction in vehicle-relates taxes, generally } \\
\text { ranging from } \$ 100 \text { to } \$ 500 \text { per vehicle per year }\end{array}$ & One per year & Germany \\
\hline
\end{tabular}

Regulations. As it was noted by Skinner et al. (2010), the best way to reduce greenhouse gas emissions is intensity regulation enforced by employing the national level measures which are developed with consideration of the strategic aims and compatibility with the other instruments applied. These measures commonly do not cause any additional costs for national budgets and are swiftly implemented. Their efficiency comes from the legally binding nature which obliges electric vehicle suppliers to provide the products that meet quality and safety standards 
(Windisch, 2013). For instance, the OECD/IEA (2016) emphasises the following regulatory measures: tailpipe emission regulations and fuel economy standards, sometimes including credits that favour electric cars, such as mechanisms that allow increased weight of electric vehicles when accounting for corporate average fuel economy standards. Mock (2014) analysed the case of the EU that introduced the mandatory carbon dioxide emission standards for passenger cars in 2009. Currently, carbon dioxide emissions are taxed in the largest part of the EU member states. According to Yan and Eskeland (2016), fuel tax is the first best measure that can and should be employed for reduction of exhaust emissions. Norway included carbon dioxide emissions in fuel tax estimations in 1991. With reference to Hardman (2017), fuel taxes were introduced as a measure to combat air pollution and climatic changes, and to promote consumers to buy fuel-efficient vehicles. Although this measure does not serve as a direct incentive for consumers to buy electric vehicles, it has a strong positive impact. In most EU countries fuel tax accounts for a relatively large share of fuel prices. For example, in the Netherlands, fuel tax accounts for $70 \%$ of fuel costs per litre, in Great Britain it accounts for $65 \%$ of fuel costs per litre, while in the United States it accounts for 10-15\% of fuel price per gallon. Gallagher and Muehlegger (2011) found that despite the financial incentives employed in the United States, the growth in the number of hybrid vehicles depends on the increase in fuel prices and social preferences. This finding was confirmed by Chandra et al. (2010) and Diamond (2009) who established that increasing fuel prices serve as a much greater incentive to enlarge the share of eco-friendly vehicles than employment of direct financial measures which substantially reduce the prices of eco-friendly vehicles for consumers, but at the same time are too expensive to be prospective. This tendency shows that the governmental policies to raise fuel prices can stimulate usage of electric vehicles.

Sales mandates and government quotas are also considered to be efficient regulatory tools. Californian ZEV mandates is a prominent example of such policies which have already been followed in Canada and China (Hall et al., 2017). ZEV mandates is a regulatory tool that promotes vehicle manufacturers to sell particular quantities of low emission cars and/or zero emission cars (Global EV Outlook, 2017). This tool is considered to have a consistent long-term perspective.

Another type of incentive is employed in China where electric vehicle drivers can acquire vehicle registration plates at preferential terms. For instance, for acquisition of a vehicle registration plate, Shanghainese traditional vehicle drivers have to participate in an auction where only $5 \%$ of the participants successfully acquire a vehicle registration plate; for acquisition of a vehicle registration plate in Beijing, traditional vehicle drivers have to take part in a lottery (Wang et al., 2017). As it was noted by Hanley (2011), while assessing the impact of national authorities on promotion of electric vehicles, it is important to understand that national authorities often set the game rules that have to be accepted by local authorities. The role of local authorities in promotion of electric vehicles will be discussed in the following section of this article.

\section{The Role of Local Authorities}

National authorities can select a specific set of promotion measures with consideration of peculiarities of the current system, universal needs and financial capacities that depend on characteristics of a country, including its geographical position and economic situation (Windisch, 2013). Regardless of the power of national authorities, it should not be overlooked that local authorities are closer to consumers. Therefore, local policies, which promote usage of electric vehicles, can create additional incentives not only for individual consumers, but also for business companies (Kampman et al., 2011). Before national or global implementation of promotive measures, cities can play a leading role in developing and testing innovative policies. In 2015, nearly one-third of global car sales occurred in 14 cities worldwide (Hall et al., 2017). The issue of air quality is the main driving force for cities to stimulate usage of electric vehicles. It is no wonder that the cities which serve as urbanisation centres often occupy larger electric vehicle market shares in comparison to country averages (IEA/OECD, 2017). In 2015, the sales of electric vehicles amounted to only $0.8 \%$ of the new car sales worldwide. Oslo (27\%), Utrecht (15\%), Shanghai (11\%), Shenzhen (10\%), Amsterdam (10\%) and San Jose (9.4\%) are the cities leading in the sales of new electric passenger vehicles. By the general statistics for 2015, Shanghai, Los Angeles, and Beijing occupied the leading positions with 18,000 42,000 new electric vehicle registrations (Hall et al., 2017).

In order to be effective, a well-balanced and comprehensive promotive policy package has to incorporate all types of measures: framework conditions, network management, communication and information diffusion, fleet procurement, economic incentives, and policy supporting multimodal transport (Windisch, 2013). What is more, it is important to remember that cities are not closed systems. Hanley (2011) notes that implementation of the largest part of the schemes calls for co-operation with neighbourhoods on the most popular regional routes which can make more significant effects on environment in comparison to local routes. Comprehensive local stimulation policies can substantially prompt the spread of electric vehicles in the market. On the other hand, promotion of electric vehicles should be a self-serving goal, notable in the context of greenhouse gas emission reduction. For this reason, promotive programs have to be continuously assessed to prevent the occurrence of rebound effects. (Kampman et al., 2011). According to Windisch (2013), although the measures implemented at the national level significantly contribute to the spread of electric vehicles, the measures implemented at the local level are more influential. Only local authorities are aware of local environment, consumer expectations, mobility needs, possible restrictions and transportation problems. This awareness allows to develop the most efficient eco-friendly vehicle promotion measures that are suitable for local conditions and aligned with the budget. Kampman et al. (2011) note that stimulating policies cause costs which have to be paid by a city or a country. Hence, the larger is number of electric vehicles in the market, the higher costs have to be paid to implement promotive measures. For cost saving the 
end of implementation of promotive measures has to be planned.

Another method to increase the number of eco-friendly vehicles and enhance their visibility in cities is electrification of a city's transit and fleets. Popularity of electric buses, which is increasing year after year, is determined by some obvious advantages: electric buses can significantly reduce local noise and pollution rates. Moreover, advancement of battery technologies now allows to charge electric buses up to 6000 times, which means that the buses of this type can be exploited up to 16 years until their batteries need to be replaced (Adheesh et al., 2016). In the municipal level, usage of electric vehicles in business companies is much more sensitive to and dependent on the infrastructure of charging stations than usage of electric vehicles for personal purposes. This is determined by the activities of taxi fleets and other operators whose service is limited by political boundaries (Mersky et al., 2016). A taxi service is a ponderable polygon of a city transport infrastructure, and taxi car work cycles perfectly match the specifications of electric vehicles. Some cities, such as Amsterdam, are attempting to electrify all their city taxi fleets. Like other car sharing systems, electrified taxis can have a localisation effect; they can also normalise technologies and have direct positive impacts on the local environment (Hall et al., 2017). Further in the article, we will discuss three main areas in which local authorities play the most important role. These areas include communication, charging infrastructure and other measures.

Communication. Despite the growth in electric vehicle sales, it should not be overlooked that promotion of electric vehicles is burdened by some barriers that do not allow to exploit the full potential. The most serious barriers include the relative convenience of the technology considering range and charge times, the additional cost of the new technology, and consumer understanding about the availability and viability of electric vehicle. The latter of the barriers, referred to as 'consumer awareness', is considered to be extremely influential (Jin and Slowik, 2017). Meeting of realistic consumer expectations and promotion of the usage of electric vehicles require public education which helps to understand the real benefits and advantages of electric vehicles (Salisbury, 2011). Publicizing is the core of the initial electric vehicle development stage. This type of communication covers presentation events, workshops, preparation of published and online material, increasing exposure to electric vehicles from fleet and carsharing services, media campaigns, etc. (Jin \& Slowik, 2017). According to Hanley (2011), employment of information and marketing tools can be effective only when introduction of electric vehicle advantages and presentation of promotion measures are combined. As it was noted by Cluzel et al. (2013), local authorities possess an exceptional ability to implement all local promotion measures by exploiting the links with local population, communities and nongovernmental organisations. Moreover, local authorities can co-operate with local businesses. A supportive policy framework can contribute to building trust and opportunities, which, in turn, could help attract electricvehicle-favourable investment. In addition, electric vehicle promotion measures may help to provide new acceptance or willingness to try eco-friendly cars (Kampman et al., 2011).
As cities possess limited resources, co-operation with business helps to achieve the synergy effects that generate benefits for consumers. Co-operation between the public and private sectors in London can serve as an example. The City of London made the first large investment in charging stations, but currently the entire charging system is managed by a private enterprise, which so far has built more than 850 charging stations and is planning to arrange 4500 extra stations by the end of 2018 (IEA/OECD, 2017). Direct implementation of the electric vehicle supply equipment can be accomplished by establishing purchase contracts with charging equipment suppliers. The municipality of Oslo that built two large parking garages for electric vehicles can serve as an example of the direct investment initiative (Hall et al., 2017). With reference to Windisch (2013), in the municipal level, electric vehicles can be introduced through pilot or experimental projects. Such projects are popular in many countries. They are usually funded from public resources with an opportunity to attract private partners, for example, local business companies or car and equipment manufacturers that want to test advanced technologies. Piloting and demonstration of the best electric vehicle promotion practices can serve not only as a good example for other cities, but also as an effective teaching tool that helps to improve the cost efficiency of the policy development process (IEA/OECD, 2017). Successfully accomplished pilot and experimental projects can involve a large number of stakeholders. Co-operation with business and involvement of private enterprises provide one more advantage. The policies that motivate business enterprises to transfer to electric vehicles substantially improve the statistics of the usage of electric vehicles in cities because of large commercial fleets (Kampman et al., 2011). Most of Chinese cities offer additional consumer fiscal discounts and other promotants for acquisition of private electric vehicles and buses. The 2009-2012 program 'Ten Cities, Thousand Vehicle' was expanded to 25 cities, while the pilot city programs grew by themselves. The pilot cities employed financial incentives, charging infrastructure development and other promotion measures to raise the popularity and applicability of electric vehicles (Wang \& Liu, 2015).

Charging infrastructure. Authorities often face the 'chicken-and-egg' phenomenon: without extensive charging and filling station systems, drivers do not want to buy eco-friendly vehicles; on the other hand, it is hard to expect that extensive infrastructures will be built without the active usage of eco-friendly vehicles (Stevens \& Schieb, 2013). Perdiguero and Jimenez (2012) and Sunnerstedt (2009) make a conclusion that an extensive charging network and its continuous development are the conditions necessary for promotion of the usage of electric vehicles. What is more, not only network supply development, but also network maintenance and improvement are important determinants of the usage of electric vehicles. Arrangement of the local public recharge infrastructure is an exceptional duty of local authorities. Local public recharge infrastructures can be developed by involving the funds and private investors (Windisch, 2013). For promotion of the usage of electric vehicles, local authorities must focus on the development of recharge infrastructures at homes, works and in public areas (OECD/IEA, 2016). Each of the above- 
mentioned recharge locations is linked to different types of promotion and policy issues. Most of the experts agree that namely home charging infrastructure is one of the key determinants of electric vehicle sales promotion, especially for those, who start using electric vehicles in the initial stage of development. For instance, London City initially focused on the promotion of home charging stations, and only after that - on work charging stations and public charging stations (Salisbury, 2011). Paris municipality not only granted extra parking benefits and arranged special parking lots for electric cars, but also built electric vehicle charging stations by the Autolib electric car-sharing programme (Hall et al., 2017). In accordance with a car battery type and charging speed preferred, the owners of electric cars may need to upgrade their electrical systems at homes so that their cars could be charged by night and exploited by day. This causes extra costs and information discrepancies, which, in turn, may impede purchase of an electric vehicle. Local authorities may employ the rebates or grants for the purchase or installation of home charging equipment. Rebates can also be employed upon the purchase of equipment or monthly electricity rates can be reduced (Windisch, 2013). For instance, the municipality of Utrecht offers a $€ 500$-subsidy for arrangement of a private charging station, and a $€ 1500$-subsidy for arrangement of the semipublic charging infrastructure (Hall et al., 2017). The metropolitan area of Amsterdam have made an interesting strategic policy decision for promotion of the development of charging infrastructures: they apply the demand-based approach for zoning actions, i.e. public charging infrastructures are built only after consideration of consumer needs. Electric vehicle buyers may register their needs to have a charging station near their homes, and the municipality builds the stations or looks for private or offstreet alternatives (IEA/OECD, 2017). Rushlow et al. (2015) found that potential electric vehicle buyers are 20 times more likely to buy an electric vehicle if they have an access to a charging station in their workplace. Extensive networks composed of workplace and commercial charging stations help the utilities to manage mid-day peaks and match electric vehicle charging to solar energy. Mersky et al. (2016) found that usage of electric vehicles in the municipal level is sensitive to the average household income, while usage of electric vehicles for business purposes much depends on the number of charging stations. What concerns the arrangement of charging stations in public areas, it is important not to underestimate station building costs and to identify who is going to bear these costs. What is more, municipalities and their partners have to decide on electric vehicle charging fees, i.e. they can consider several options from free and unregulated charging when the municipality bears all the costs to introduction of the policies when the costs are borne by nearly located business companies taxed a higher utility rates. Charging station users may also pay not for charging itself, but for parking, which drives charging costs down (Salisbury, 2011). In any case, administrative procedures, including arrangement of home charging and public charging stations, have to be simplified (Windisch, 2013). Despite the difficulties to identify a clear need to have charging stations in apartment block yards, the municipal focus on arrangement of charging infrastructures in these yards is logical (Salisbury, 2011), especially minding the fact that it does not require additional public funds. In the municipal level, the additional requirements linked to the development of real estate can be identified. According to Cluzel et al. (2013), the obligation for real estate developers to arrange charging stations in new buildings is the most cost-effective method to raise the attractiveness of electric vehicle usage in workplaces and residential areas. This attitude is supported by Hanley (2011) who notes that such setting of rules hardly generates extra costs for local authorities because all the costs are borne by real estate developers. Later on, these costs are naturally included in the price of the premises on sale. Here are some examples. Vancouver City Council made the decision to amend the Building Code so that each private house could support Level 2 charging infrastructure, and $20 \%$ of apartment block parking lots could be adapted for charging of electric vehicles. San Francisco City Council obliged real estate developers to install Level 2 chargers in $10 \%$ of newly-built parking premises and prepare the equipment necessary for installation of extra $10 \%$ in the future (IEA/OECD, 2017).

Other measures. Regulation instruments, such as fuel economy standards and financial incentives to purchase electric vehicles, can be successfully created at the municipality level, while circulative incentives and the waivers to access restrictions are more commonly employed by national authorities. The advantages of well-adjusted regulatory measures and the need to act at the local level are linked to exploitation of road networks (OECD/IEA, 2016). Local authorities should promote usage of electric vehicles by providing a large and understandable value for consumers with non-financial advantages, such as preferential parking and road access (Cluzel et al., 2013). Parking regulations and zoning actions are the instruments directly linked to urban networks. While making their decisions, local authorities follow the plans of urban network exploitation and development (IEA/OECD, 2017). Such measures as preferential fees and preferential access rights are politically acceptable and easily implemented. It is common practice that such measures are accepted in the municipal level as local authorities can best define the scopes of measure implementation with consideration of traffic intensity and lack of parking lots (Windisch, 2013). This attitude is supported by Kampman et al. (2011) who note that such measures as road toll exemptions or parking rebates, which can also be important for promotion of electric vehicles, are commonly employed at the local level. According to Sunnerstedt (2009), drivers like daily benefits granted for usage of eco-friendly vehicles. This means that one-time tax exemption granted for purchase of an electric car is less effective than the offer to use a free parking lot every day. The research, carried by Litman (2016), revealed that charging of parking fees is the second efficient congestion reduction strategy, which is less efficient than employment of peak-period congestion fees, but more efficient than employment of fuel taxes and emission fees. Gradually introduced parking fees, which are politically acceptable and simply administrated, provide more benefits than time-and-location-based road pricing, implementation of which is costly and requires special infrastructures. Permission to drive high-occupancy, bus or transit lanes is another measure that may contribute to promotion of 
electric vehicle usage. According to Ta1 and Nicholas (2014), permission to drive high-occupancy vehicle lanes is an important non-monetary promotion measure. Hardman (2017) states that in order to prevent jamming of highoccupancy vehicle lanes, the lanes should be made available only to the vehicles with two or more passengers; in addition, lane exploitation time can be fixed. Tal and Nicholas (2014) present the example of California where high-occupancy vehicle lanes can be used only with special access permissions: white stickers can be acquired by an unlimited number of low-emission vehicle drivers. With reference to Van der Steen et al. (2015), the research in
California revealed that $59 \%$ of the respondents treated access to high-occupancy vehicle lanes as an extremely important determinant of their decision to purchase an electric vehicle. Bjerkan et al. (2016) note that access to bus lanes is an incentive that does not require governmental expenditure, and therefore can be employed as a marketing tool in small and medium-sized cities till the number of electric vehicles reaches the rate when electric vehicles become a burden to regular public transport flows. Hanley's (2011) matrix of the incentives that can be implemented by local authorities to promote usage of electric vehicles has been presented in Table 2 .

Table 2

Matrix of the Incentives that Can be Implemented by Local Authorities to Promote Usage of Electric Vehicles (Hanley, 2011, 38-41)

\begin{tabular}{|c|c|c|c|c|}
\hline Incentive & Pros & Cons & Overall effective-ness & Local authority appetite \\
\hline $\begin{array}{l}\mathrm{CO} 2 \text {-based parking } \\
\text { policy }\end{array}$ & $\begin{array}{l}\text { Forms a part of a fiscal } \\
\text { incentive package for } \\
\text { consumers }\end{array}$ & $\begin{array}{l}\text { Potential loss of revenue for local } \\
\text { authorities as vehicles become } \\
\text { more efficient }\end{array}$ & High & $\begin{array}{l}\text { High for resident permits, can } \\
\text { only play an advisory role for } \\
\text { workplaces }\end{array}$ \\
\hline $\begin{array}{l}\text { Free parking } \\
\text { for low carbon } \\
\text { vehicles }\end{array}$ & $\begin{array}{l}\text { Targets electric } \\
\text { vehicles and lowest- } \\
\text { emission vehicles }\end{array}$ & $\begin{array}{l}\text { Could contravene the policies to } \\
\text { reduce } \\
\text { car-based traffic in town centres }\end{array}$ & Medium & $\begin{array}{l}\text { High (the most common } \\
\text { measure) }\end{array}$ \\
\hline $\begin{array}{l}\text { Public charging } \\
\text { infrastructure }\end{array}$ & $\begin{array}{l}\text { Contributes to electric } \\
\text { and hybrid vehicle } \\
\text { market growth }\end{array}$ & $\begin{array}{l}\text { Current consumers may prefer } \\
\text { home charging due to the time } \\
\text { needed to reach full charge }\end{array}$ & Medium & High \\
\hline $\begin{array}{l}\text { Home charging } \\
\text { infrastructure }\end{array}$ & $\begin{array}{l}\text { Convenient for low } \\
\text { carbon vehicle } \\
\text { consumers }\end{array}$ & $\begin{array}{l}\text { In the areas without offstreet, } \\
\text { private parking it is difficult to } \\
\text { retro-fit points on-street to enable } \\
\text { guaranteed overnight charging for } \\
\text { all residents }\end{array}$ & High & Low \\
\hline $\begin{array}{l}\text { Charging points in } \\
\text { new developments }\end{array}$ & $\begin{array}{l}\text { Convenient for low } \\
\text { carbon vehicle } \\
\text { consumers }\end{array}$ & $\begin{array}{l}\text { Points will still need to be } \\
\text { communal for city centre } \\
\text { residences without garages or } \\
\text { driveways }\end{array}$ & High & $\begin{array}{l}\text { High (but the role of local } \\
\text { authorities vs. energy } \\
\text { suppliers needs clarification) }\end{array}$ \\
\hline $\begin{array}{l}\text { Reduced business } \\
\text { rates for those with } \\
\text { low carbon vehicle } \\
\text { fleets }\end{array}$ & $\begin{array}{l}\text { Could be effective in } \\
\text { Air Quality } \\
\text { Management Areas } \\
\text { where EU fines for } \\
\text { local authorities not } \\
\text { meeting monitoring } \\
\text { targets can be reduced }\end{array}$ & $\begin{array}{l}\text { Local authorities may lose } \\
\text { revenue in the short term }\end{array}$ & Potentially high & Low \\
\hline $\begin{array}{l}\text { Road pricing and } \\
\text { exemptions for low } \\
\text { carbon vehicles }\end{array}$ & $\begin{array}{l}\text { Effective at reducing } \\
\mathrm{CO} 2 \text { through both } \\
\text { demand reduction and } \\
\text { easing traffic flows }\end{array}$ & $\begin{array}{l}\text { Politically unpopular, issues } \\
\text { around whether road pricing } \\
\text { should be a congestion charge or } \\
\text { an emission-based charge }\end{array}$ & High & Low \\
\hline $\begin{array}{l}\text { Public procurement of } \\
\text { low carbon vehicle } \\
\text { fleets }\end{array}$ & $\begin{array}{l}\text { Purchasing discounts } \\
\text { can be amplified by } \\
\text { setting up joint } \\
\text { procurement } \\
\text { frameworks }\end{array}$ & $\begin{array}{l}\text { Break-even point for most vehicle } \\
\text { fleets is still in favour of internal } \\
\text { combustion engine vehicles }\end{array}$ & Medium & High \\
\hline $\begin{array}{l}\text { 'Low carbon vehicles } \\
\text { only' lanes and access } \\
\text { to bus lanes }\end{array}$ & $\begin{array}{l}\text { Promotes journey time } \\
\text { saving benefits for low } \\
\text { carbon vehicle users }\end{array}$ & $\begin{array}{l}\text { Potential road safety impacts on } \\
\text { cyclists and motorcyclists }\end{array}$ & High & Medium \\
\hline $\begin{array}{l}\text { Route/Access } \\
\text { restrictions except for } \\
\text { low carbon vehicles }\end{array}$ & $\begin{array}{l}\text { Could help to reduce } \\
\text { air pollution in inner- } \\
\text { city areas }\end{array}$ & $\begin{array}{l}\text { Potential road safety impacts on } \\
\text { cyclists and pedestrians }\end{array}$ & Low & Low \\
\hline $\begin{array}{l}\text { Low Emission Zones } \\
\text { (LEZs) }\end{array}$ & $\begin{array}{l}\text { Can reduce emissions } \\
\text { over a wide area }\end{array}$ & Expensive to set up and enforce & High & Medium \\
\hline $\begin{array}{l}\text { Information and } \\
\text { marketing }\end{array}$ & $\begin{array}{l}\text { Helps consumers to } \\
\text { make an informed } \\
\text { choice }\end{array}$ & $\begin{array}{l}\text { Likely to be effective only in } \\
\text { combination with incentives and } \\
\text { attractiveness of vehicles }\end{array}$ & Medium & High \\
\hline
\end{tabular}

In some cities or countries, electric vehicle drivers are exempted from congestion fees charged in the areas with high traffic intensity, for instance, London City. Although daily fees are commonly charged for the entrance to high traffic intensity areas, zero-emission vehicles are exempted from these fees (Lache et al., 2009). Exemptions from road and traffic congestion fees are also applied in China,
Germany, Japan, Norway and Sweden (Hardman, 2017). The study, carried out by Windisch (2013), revealed that implementation of such measures at the national level is more an exception than a rule. For example, China implements such measures only in electric vehicle demonstration cities, Portugal - in urban centres, etc. Norway is one of the countries where preferential fees and 
access rights are implemented at the national level. As it was noted by Kley et al. (2010), congestion charge effects as well as effects of the other municipality-level promotion measures are hard to evaluate because they are strongly influenced by local contexts and consumer patterns.

\section{Assessment of the Policy Frameworks Implemented by Different Authorities}

In many cases, electric vehicle promotion measures implemented by national and local authorities differ due to the variance of the focus areas, which are determined by the scopes of promotion systems. According to Hanley (2011), the schemes of small-scope promotion mechanisms work best when they focus on particular journey interchange, such as train stations, bus stations, airports or park-and-ride locations where electric cars can be left for charging for a few hours. However, the differences between local and national promotion levels lie not only in the scopes of promotion systems. The spectrum of activities depends on physical and political context of the location. For instance, uneven Norwegian terrain provides favourable opportunities to charge fees for the usage of the most popular tunnel and exempt electric vehicles from these fees; Shanghainese transport quota system provides the opportunities to facilitate registration of electric vehicles, etc. (Hall et al., 2017). Current transport infrastructures and their links with transportation systems are also important. For example, the owners of electric vehicles in Norway pay lower fees for ferry services (Hardman, 2017); in 2015, the State of Washington introduced the strategy of electric vehicle usage promotion which approved reduction of ferry service fees for eco-friendly cars (Buell, 2015). The review of the key differences between the focus areas and promotion measures implemented at the national and local administrative levels has been presented in Table 3.

Table 3

The Differences between the Focus Areas and Promotion Measures Implemented at the National and Local Administrative Levels (Compiled by the Authors)

\begin{tabular}{|c|c|c|}
\hline \multirow{2}{*}{$\begin{array}{l}\text { Administrative } \\
\text { levels }\end{array}$} & \multicolumn{2}{|r|}{ Policy framework } \\
\hline & Focus areas & Examples of measures \\
\hline National & $\begin{array}{l}\text { Setting national goals; } \\
\text { Standardizations; } \\
\text { Regulations; } \\
\text { Deployment of charging infrastructures; } \\
\text { Financial initiatives; } \\
\text { Marketing. }\end{array}$ & $\begin{array}{l}\text { - Exemption from VAT; } \\
\text { - Direct subsidies for vehicle consumers; } \\
\text { - Tax credits; } \\
\text { - Financial support for car manufacturers; } \\
\text { - Incentives in energy taxation/vehicle registration taxes; } \\
\text { - Annual vehicle tax reduction; } \\
\text { - Initiatives for public charging infrastructure; } \\
\text { - Regulation of charging infrastructure; } \\
\text { - } \text { - } \text { Cap and regulation incentives; } \\
\text { - Green public procurement; } \\
\text { - Obligation for new constructions; } \\
\text { - R\&D stimulation; } \\
\text { - Sales mandates; } \\
\text { - Promotion campaigns. }\end{array}$ \\
\hline Local & $\begin{array}{l}\text { Setting local goals; } \\
\text { Marketing; } \\
\text { Parking policy; } \\
\text { Traffic management tools; } \\
\text { Urban access restrictions; } \\
\text { Fleets upgrade; } \\
\text { Private and public partnerships; } \\
\text { Deployment of charging infrastructures; } \\
\text { Financial initiatives. }\end{array}$ & $\begin{array}{l}\text { - Initiatives for home/business/public charging infrastructure; } \\
\text { - Regulation of charging infrastructures; } \\
\text { - Obligation for new constructions; } \\
\text { - Fleet tests and demonstration programs; } \\
\text { - Incentives in parking policies; } \\
\text { - Bus lane incentives; } \\
\text { - Road pricing incentives; } \\
\text { - Congestion taxes; } \\
\text { - Low-emission zone incentives; } \\
\text { - Route/Access restrictions; } \\
\text { - Promotion campaigns; } \\
\text { - Consulting. }\end{array}$ \\
\hline
\end{tabular}

Consideration of several types of plausible risks is also purposeful. Although it is the case that electric vehicles are exempted from road taxes, granted free parking and the access to bus lanes, which, in turn, significantly contributes to usage of electric vehicles, it should not be overlooked that all of the measures sustainably work only till high levels of vehicle concentration are reached (Windisch, 2013). The experience of Gothenburg shows that electric vehicle promotion policies may have serious side effects (Sunnerstedt, 2009). Free parking grants for all eco-friendly car drivers promote driving and can cause the transfer from public transport to private transport. Despite the advantages of eco-friendly vehicles and the necessity to promote the usage of electric vehicles, possible drawbacks of active implementation of promotion measures should be considered. For successful results, the problems linked to implementation of promotion measures have to be minimised (Perdiguero \& Jimenez, 2012), and all the promotion potential has to be exploited (Kampman et al., 2011). The future directions of electric vehicle promotion may include delivery services, postal fleets and public fleets, such as parking enforcement or taxi cab services. 


\section{Conclusions}

The above-analysed examples of electric vehicle promotion indicate that complementation of national policy schemes with local policy measures may help to create electric vehicle-favourable environment and reduce barriers for consumers. Development of charging infrastructures, considered to be the key determinant of electric vehicle promotion, is the responsibility of both national and local authorities: national authorities set the standards and build highway infrastructures, while local authorities take care of arrangement of charging points in each of microdistricts. Arrangement of charging points can be treated not only as a promotive measure, but also as building of the necessary infrastructure.

In the initial stage of electric vehicle promotion, the actions of national authorities that set the political aims of general planning and co-ordination serve as a signal to manufacturers and service provides about the changes in the demand for electric vehicles in the future. Standardisation along with economic and regulatory mechanisms can be treated as the other key instruments. The main purpose of financial incentives is to reduce electric vehicle prices or usage costs so that the critical differences between electric and traditional vehicle costs would be eliminated. Regulatory mechanisms can cause side effects for the substitutes of electric vehicles. The decisions of national authorities may affect fossil fuel prices, while the growth of petrol and diesel prices may directly affect the usage of alternative means of transportation. In this case, sales mandates, which fix the proportion of electric vehicles in the total number of newly-sold vehicles, can be introduced. The other method is provision of electric vehicle purchase subsidies only for domestically made vehicles.
Summarising, it can be stated that the actions of national authorities are concentrated at the macro level.

Despite significance of the role of national authorities, it is also the case that local authorities are closer to consumers, and therefore can more efficiently communicate with all social groups and co-operate with business, which, in turn, helps to create synergy by employing not only financial and non-financial measures, but also marketing campaigns, consulting and provision of the basic information. Local authorities can also take the initiative to reform car, public transport and taxi fleets. They have a direct impact on the micro-level focus areas which are linked to traffic and transport regulation: parking policies, traffic management tools and urban access restrictions. Such benefits as convenience and cost saving opportunities are effective electric vehicle purchase and usage motivators.

The findings of this research do not propose that the functions of national and local authorities never duplicate, and the similar or same financial and non-financial measures are never employed at the national and local levels. On the contrary, adjustment of national and local actions along with a comprehensive approach towards electric vehicle promotion can significantly enhance the efficiency of the measures applied. Regions (the role of which has not been comprehensively analysed in this article) are intermediates between national and local authorities. It should be noted that the conclusions of this research on the functions of national and local authorities reflect the regular trends. However, in some cases, irregular administrative distributions can be found. Hence, as sets of municipal functions and powers may differ, the measures implemented in particular jurisdictions not necessarily suit other jurisdictions.

\section{References}

Adheesh, S., R., Vasisht, M., S., \& Ramasesha, S., K. (2016). Air - Pollution and Economics: Diesel Bus Versus Electric Bus. Current Science, 110 (5). Available from internet: http://www.currentscience.ac.in/Volumes/110/05/0858.pdf

Alhulail, I., \& Takeuchi, K. (2014). Effects of Tax Incentives on Sales of Eco-Friendly Vehicles: Evidence from Japan. Discussion paper no. 1412. Graduate School of Economics, Kobe University.

Bjerkan, K., Y., Norbech, T., E., \& Nordtomme, M., E. (2016). Incentives for Promoting Battery Electric Vehicle (BEV) Adoption in Norway. Transportation Research Part D: Transport and Environment, 43, 169-180. https://doi.org/10.101 6/j.trd.2015.12.002

Buell, T. (2015). Washington State Electric Vehicle Action Plan 2015-2020. Washington State Department of Transportation. Available from internet: http://www.wsdot.wa.gov/NR/rdonlyres/28559EF4-CD9D-4CFA-9886105A30FD58C4/0/WAEVActionPlanFebruary2015Print.pdf

Chandra, A., Gulati, S., \& Kandlikar, M. (2010). Green Drivers or Free Riders? An Analysis of Tax Rebates for Hybrid Vehicles. Journal of Environmental Economics and Management, 60, 78-93. https://doi.org/10.1016/j.jeem.2010.04.003

Cluzel, C., Lane, B., \& Standen, E. (2013). Pathways to High Penetration of Electric Vehicles. Final report for The Committee on Climate Change. Available from internet: https://www.theccc.org.uk/wp-content/uploads/2013/12/CCCEV-pathways_FINAL-REPORT_17-12-13-Final.pdf

Diamond, D. (2009). The Impact of Government Incentives for Hybrid-Electric Vehicles: Evidence from US States. Energy Policy, 37 (3), 972-983. https://doi.org/10.1016/j.enpol.2008.09.094

Eppstein, M., J., Grover, D., K., Marshall, J., S., \& Rizzo, D., M. (2011). An Agent-Based Model to Study Market Penetration of Plug-in Hybrid Electric Vehicles. Energy Policy, 39, 3789-3802. https://doi.org/10.1016/j.enpol.2011.04.007

Gallagher, K., S., \& Muehlegger, E. (2011). Giving Green to Green? Incentives and Consumer Adoption of Hybrid Vehicle Technology. Journal of Envirnmental Economis and Management, 61 (1), 1-15. https://doi.org/10.1016/j.jee m.2010.05.004 
Povilas Maciulis, Inga Konstantinaviciute, Vaida Pilinkiene. Assessment of Electric Vehicles Promotion Measures at the...

Gao, P., Malorny, C., Sha, S., Guan, M., Wu, T., Luk, T., Yang, L., Lin, D., \& Xu, X. (2015). Supercharging the Development of Electric Vehicles in China. McKinsey\&Company. Available from internet: http://www.mckinseychina.com/wpcontent/uploads/2015/04/McKinsey-China_Electric-Vehicle-Report_April-2015-EN.pdf

Hall, D., \& Lutsey, N. (2017). Literature Review on Power Utility Best Practices Regarding Electric Vehicles. International Council On Clean Transportation. Available from internet: https:/www.theicct.org/sites/default/files/publications/ Power-utility-best-practices-EVs_white-paper_14022017_vF.pdf

Hall, D., Moultak, M., \& Lutsey, N. (2017). Electric Vehicle Capitals of the World: Demonstrating the Path to Electric Drive. International Council on Clean Transportation. Washington, DC. Available from internet: www.theicct.org/sites/default/files/publications/Global-EV-Capitals_White-Paper_06032017_vF.pdf

Hanley, C. (2011). Going Green: How Local Authorities Can Encourage the Take-Up of Lower-Carbon Vehicles. Royal Automobile Club Foundation. Available from internet: https://www.racfoundation.org/wp-content/uploads/2017/ 11/61442_racf_lcv-and-la-powers-author-buchanan_aw.2_web.pdf

Hardman, S. (2017). Reoccurring and Indirect Incentives for Plug-In Electric Vehicles - a Review of the Evidence. Plug-in Hybrid and Electric Vehicle Research Center. Institute of Transportation Studies. University of California, Davis;

ICCT (2017). Adjustment to Subsidies for New Energy Vehicles in China. Policy update. International Council On Clean Transportation. Available from internet: https://www.theicct.org/sites/default/files/publications/China-NEV_ICCT _policy -update_17052017_vF.pdf

IEA/OECD (2017). Global EV Outlook 2017: Two Million and Counting. International Energy Agency. Available from internet: https://www.iea.org/publications/freepublications/publication/GlobalEVOutlook2017.pdf

IEA-RETD (2015). Driving Renewable Energy for Transport - Next Generation Policy Instruments for Renewable transport (RES-T-NEXT). IEA Implementing Agreement for Renewable Energy Technology Deployment (IEA-RETD). Utrecht. Available from internet: http://iea-retd.org/wp-content/uploads/2015/12/IEA-RETD-RES-T-NEXT-201511.pdf

Jin, L., \& Slowik, P. (2017). Literature Review of Electric Vehicle Consumer Awareness and Outreach Activities. International Council on Clean Transportation. Available frominternet: https://www.theicct.org/sites/default/files/ publications/Consumer-EV-Awareness_ICCT_Working-Paper_23032017_vF.pdf

Kampman, B., Essen, H., Braat, W., Grünig, M., Kantamaneni, R., \& Gabel, E. (2011). Impacts of Electric Vehicles Deliverable 5. Impact analysis for market uptake scenarios and policy implications. Delft, CE Delft, 11.4058.07.

Kley, F., Wietschel, M., \& Dallinger, D. (2010). Evaluation of European Electric Vehicle Support Schemes. Working paper sustainability and innovation, S7/2010. Available from internet: http://hdl.handle.net/10419/40019

Lache, R., Galves, D., Nolan, P., Sanger, K., Kitaura, T., Gehrke, J., Toulemonde, G., Rokossa, T., Rana, S., Chang, S., \& Ha, V. (2009). Electric Cars: Plugged In 2. A Mega-Theme Gains Momentum. Global Markets Research. United States. Available from internet: http://www.libralato.co.uk/docs/Electric\%20Cars\%20Plugged\%20In\%202\%20Deutsche\% 20Bank\%202009.pdf

Leviakangas, P., Kinnunen, T., \& Kess, P. (2014). The Electric Vehicles Ecosystem Model: Construct, Analysis and Identification of Key Challenges. Managing Global Transitions, 12 (3), 253-27.

Litman, T. (2016). Parking Pricing Implementation Guidelines: How More Efficient Parking Pricing Can Help Solve Parking and Traffic Problems, Increase Revenue, and Achieve Other Planning Objectives. Victoria Transport Policy Institute.

Mak, K., Sanchez, E., \& Li, K. (2017). China Zero Emission Vehicle Requirement Mandate Boosts Battery Electric Powertrain Demand. The Strategy Analytics report.

Mersky, A. C., Sprei, F., Samaras, C., \& Qian, Z. (2016). Effectiveness of Incentives on Electric Vehicle Adoption in Norway. Transportation Research Part D: Transport and Environment, 46, 56-68. https://doi.org/10.1016/j.trd.2 016.03.011

Mock, P., \& Yang, Z. (2014). Driving Electrification: a Global Comparison of Fiscal Incntive Policy for Electric Vehicles. International Council on Clean Transportation.

OECD/IEA (2016). Global EV Outlook 2016: Beyond one million electric cars. International Energy Agency.

Perdiguero, J., \& Jimenez, J., L. (2012). Policy Options for the Promotion of Electric Vehicles: a Review. Working Paper. Research Institute of Applied Economics.

Rushlow, J., Coplon-Newfield, G., LeBel, M., \& Norton, E. (2015). Charging Up: The Role of States, Utilities, and the Auto Industry in Dramatically Accelerating Electric Vehicle Adoption in Northeast and Mid-Atlantic States. Conservation Law Foundation. Sierra Club and Acadia Center. Available from internet: https://www.sierraclub.org/ sites/www.sierraclub.org/files/uploads-wysiwig/Charging Up_DIGITAL_ElectricVehicleReport_Oct2015_0.pdf

Salisbury, M. (2011). What Can Cities and Counties Do to Promote the Deployment of Electric Vehicles? Southwest Energy Efficiency Project. Oak Ridge National Laboratory.

Skinner, I., van Essen, H., Smokers, R., \& Hill, N. (2010). Towards the Decarbonisation of EU's Transport Sector by 2050. Final report produced under the contract ENV.C.3/SER/2008/0053 between European Commission Directorate-General Environment and AEA Technology plc. Available from internet: www.eutransportghg2050.eu 
Stevens, B., \& Schieb, P., A. (2013). Developing Infrastructure for Alternative Transport Fuels and Power-Trains to 2020/2030/2050. A Synthesis Report. OECD.

Sunnerstedt, E. (2009). Promoting Clean Cars. Case Study of Stockholm and Sweden. European project BEST - Bioethanol for Sustainable Transport.

Tal, G., \& Nicholas, M., A. (2014). Exploring the Impact of High Occupancy Vehicle (HOV) Lane Access on Plug-In Vehicle Sales and Usage in California. Research Report - UCD-ITS-RR-14-16.

Van der Steen, M., Van Schelven, R., M., Kotter, R., Van Twist M., J., W., \& Van Deventer MPA, P. (2015). EV Policy Compared: an International Comparison of Governments' Policy Strategy Towards E-Mobility. E-Mobility in Europe: Trends and Good Practice. Springer International, 1.

Wang, N., Liu, Y. (2015). City Readiness System Assessment of Electric Vehicle Adoption in China. SAE International Journal of Materials and Manufacturing, 8 (3), 678-684. https://doi.org/10.4271/2015-01-0469

Wang, Y., Sperling, D., Tal, G., \& Fang, H. (2017). China's Electric Car Surge. Energy Policy, 102, $486-490$. https://doi.org/10.1016/j.enpol.2016.12.034

Windisch, E. (2013). Driving electric? A Financial Analysis of Electric Vehicle Policies in France. Statistical Finance. Ecole des Ponts ParisTech.

Xylia, M., \& Silveira, S. (2017). On the Road to Fossil-Free Public Transport: the Case of Swedish Bus Fleets. Energy Policy, 100, 397-412. https://doi.org/10.1016/j.enpol.2016.02.024

Yan, S., \& Eskeland, G., S. (2016). Greening the Vehicle Fleet: Evidence From Norway's CO2 Differentiated Registration Tax. NHH Dept. of Business and Management Science Discussion Paper, 2016/14. https://doi.org/10.2139/ssrn.2834804

Yang, Z., Slowik, P., Lutsey, N., \& Searle, S. (2016). Principles for Effective Electric Vehicle Incentive Design. International Council on Clean Transportation. Washington, DC. Available from internet: https://www.theicct.org/sites/default/files/ publications/ICCT_IZEV-incentives-comp_201606.pdf

The article has been reviewed. Received in January, 2018; accepted in October, 2018. 